\title{
Designing English for Civil Engineering Students
}

\author{
Sukma Yudistira, M. Zaim, and Hamzah \\ English Language Education Program \\ Universitas Negeri Padang \\ Padang, Indonesia \\ sukmayudistira@yahoo.com, mzaim@ fbs.unp.ac.id, zzahham@gmail.com
}

\begin{abstract}
Technology and economic developments are in line with the need of English skills for specific fields, including English for Civil Engineering. In preparation for graduates, Civil Engineering Department of Universitas Negeri Padang provides English for Civil Engineering course. The acceptance of graduates in employment increases, especially, for the fresh graduates who are mastering English in their area of expertise. This study investigates the need analysis of the students who are learning English for civil engineering. This research was conducted using survey method. Research data was taken through questionnaires and interviews with students, lecturers, and corporate leaders. From the result of need analysis, it was found the English skills, the teaching methodology, the topic, and the language focus needed by the civil engineering students. The results of this study provide recommendations for the development of English for Civil Engineering curriculum.
\end{abstract}

Keywords—English for civil engineering, needs analysis, English skills

\section{INTRODUCTION}

The development of world technologies and economies in the last decades is in line with the needs of using English as a medium of communication for businesses and education. Most of developing and developed companies expect their employee is having an adequate communication in English besides their major fields. Jawhar, in Yasin et al. (2010), states that in the private sector, graduates are becoming unemployable as a result of lack of proficiency in the English language. It means that English proficiency is equally important to the employees' principal field. Furthermore, since the graduates of an education institution, university, or college are prepared to work in a specific kind of job, the same as companies expectation, it is better for them to be taught English which is specified for communication in their major field. The English learning should be able to lead the students to learn English related to their major area appropriately, effectively, and efficiently, so that the learning English can be meaningful and helpful for the students in facing the real work challenges.

Due to the English skill required at work, the English course at higher education needs to be correlated with the students' needs for a certain target situation. The course then should provide broadly English knowledge related to the students' major field. The focus of specifiable content of the course is not only on specific language features, vocabulary, or grammar but also on what skills needed by the learners in communication using English in the workplace (Hutchinson, 1987). Consequently, English course should facilitate the students with relevant English skill which can support their professional career. As the subject of this research, the Civil Engineering Department (CED) of Universitas Negeri Padang (UNP) provide a specific English course for Civil Engineering students which is called English for Civil Engineering (ECE). The course is designed by using English for Specific Purposes (ESP) approach since the field of the study is in the vocational study; preparing an individual for work or a group of work, and also developing them in the field of work itself. Hutchinson and Waters (1987) state that ESP is not a learning methodology but an approach to learning English which is based on the learners' needs.

ESP has functioned to help language learners to cope with the features of language and to develop the competencies needed to perform in a discipline, profession, or workplace (Basturkmen, 2006). Moreover, Dudley-Evans and St John in Harding (1998) state that ESP is designed to meet specific needs of the learners. It makes use of the underlying methodology and activities of the discipline it serves, and it is centered on the language components (grammar, lexis, register), skills, discourse and genres appropriate to the activities. Therefore, the aim of the course of English for Civil Engineering is the students have the ability to function English terminologies used in the field of civil engineering and communicating any technical specifications of civil engineering, especially in the field of civil engineering. This course should be able to lead the students to have good English skills related to their target situation or civil engineering field to support their career later. Robinson (1991) points out that ESP courses are taught to adults in similar classes in term of the work or specialist studies that the students are involved in. Also Streven and Robinson (1991) state that ESP learners come from the similar field of education or profession as well as having the same level of English proficiency.

Based on the tracer study conducted by CED in 2012, it was found that about thirteen percent of CED UNP graduates were unemployed, although, the workplaces which are targeted by the graduates, such as construction services firms, project management consulting services, and detailed engineering design consulting services, lecturers, and vocational teachers, provide a large number of job opportunities for the graduates. In addition, several kinds of job, such as planning, scheduling, supervising, 
drafter, estimator, firms/project administration, technical facilitation, making project report, and project presentation, are using English. It means that the number of unemployment of CED graduates can be reduced by improving their English communication skill. Moreover, the capability to compete with the other universities graduates is also low. The tracer study showed that most of the CED graduates work in a local company, only few CED graduates work in multinational corporations.

To create an appropriate course, the English for Civil Engineering course should be updated by conducting need analysis (Chovancova, 2014). Richards (2001) explains that need analysis can be used for many different purposes. Some of them are (1) to find out what language skills a learner needs in order to perform a particular role, such as sales manager, tour guide, or university students, (2) to help determine if an existing course adequately addresses the needs of potential students, (3) to determine which students from a group are most in need of training in particular language skills, (4) to identify a change of direction that people in a reference group feel is important, (5) to identify a gap between what students are able to do and what they need to be able to do, (6) to collect information about a particular problem learners are experiencing, and (7) to determ the gaps between acquired and required skills for CE students. These issues can be identified by using needs analysis.

Pratt (1980) defines needs analysis as need assessment, an array of procedures for identifying and validating needs and establishing priorities among them. Brown (1995) describes needs analysis as the activities involved in gathering information that will serve as the basis for developing a curriculum that will meet the learning needs of a particular group of students. It implies that the result of need analysis could not be generalized to all of the students coming from the various field of studies or profession. In addition, Grabowski in Seel and Dijkstra (2008) state that needs analysis refers to the analysis phase during which many perspectives about a task are gathered to determine the cause of a gap between the ideal performance and the actual performance. It is supported by Nations and Macalister (2010: 24) who state that needs analysis is the procedure to examine what the learner has known already and what they need to know. Based on these definitions, it can be concluded that needs analysis is an effort to find out what the problem existed which causes the actual performance not meet the ideal performance. Need analysis is expected to provide information for a curriculum development by revealing the gap existed.

This research investigated the needs of learning English for Civil Engineering students of CED by (1) assessing the learning and target needs of civil engineering students', and (2) determining the importance of English skills needed on the job of civil engineering. This research then provided information for the curriculum development of ECE course.

\section{METHOD}

This research is intended to identify the students' needs which are viewed from the participants' point of views. In collecting the data, questions which are covered in questionnaire and interview guide are addressed to gain information about thoughts and opinions of groups of people on what the students' really need to learn. This research has the characteristics of survey research. Survey research is a procedure in quantitative research in which investigators administer a survey to a sample or to the entire population of people to describe attitudes, opinions, behaviors, or characteristics of the population (Creswell, 2008). Survey research involves collecting data to test a hypothesis or to answer questions about people's opinion on some topics or issues (Gay, 2009). There were two sets of questionnaires administered in this research. They were used to collect information from the students and companies manager about their expectation in learning English. The questionnaire items were developed based on the framework proposed by Hutchinson and Waters (1987) which had been reflected in the research questions. The questionnaire was in the form of semi closed-ended items. The students and the company managers were taken as the respondents of this research. The respondents simply put a check in the space given that best reflects their opinion on each statement. The interview guide in this research was designed for collecting the data about the students' target needs. This was addressed to the companies' managers, the chairman of Management Department and the lecturer. The interview was done in a semi-structured interview.

\section{Learning Needs}

\section{FINDING AND DISCUSSION}

The learning need analysis has revealed some relevant information about what the learner needs to learn ECE. The learning need analysis result shows that most of the students' reasons taking the ECE course are for applying job and career after graduating their study. The chairman and lecturers of CED said that the purpose of the ECE course is to enable the students to communicate with English in field of Civil Engineering and use the terminology civil engineering in the target situation. This is in line with the characteristics of ESP which is stated by Dudley-Evans and St John in Harding (1998:6) and Basturkmen (2006:6) that ESP is carried out to help language learners cope with the features of language and to develop the competencies needed to function in a discipline, profession, or workplace. Thus, the civil engineering students need ECE for preparing themselves to face the field work by equipping them with the appropriate English skills.

The teaching methods of ECE should be based on the first principle of effective and efficient learning proposed by Hutchinson and Waters (1987). The learners need to learn ECE through role play and group discussion by using pictures, films, and videos. In fact, these teaching methods may use much time if applying in ESP class, while the available time is only two hours in a week. Thus, in order the fulfill the learners' needs, the learning activity of ECE should be used effectively and efficiently in the available limited time. The time constraints issue was covered through the use of Blended learning approach in order the ECE class 
becoming effective and efficient. Blended learning activities can be managed inside and outside classroom. It is the combination of traditional learning with web-based online learning. The strengths of blended learning, according to Marsh (2012:10), is it provides a more individualized learning experience, more personalized learning support, and encourages independent and collaborative learning. Blended learning increases students' engagement in learning, accommodates a variety of learning styles, provides a place to practice the target language beyond the classroom, a less stressful practice environment for the target language, a flexible study, anytime or anywhere to meet learners' needs, and helps students develop valuable and necessary twenty-first century learning skills. By considering the strengths of the blended learning, it can lead the teaching methods of ECE carried out effectively and efficiently.

The learning sources expected by the students are authentic and designed for language teaching. The students hoped that the learning materials that can guide them to practice their language out of the classroom. The students also need to be taught by English lecturers having sufficient knowledge about Civil Engineering. Paltridge and Starfield (2013) state that a critical feature of an ESP course is that the content and aims of the course are oriented to the specific needs of the learners. The existing learning materials used in ECE were learning materials compiled by the lecturers and were not covered the students' needs and difficult for the students. It means that there is a gap between the existing materials and the expected materials. Therefore, the learning materials of ECE need improvement to cover the students' needs.

One of the characteristics of ESP, as stated by Dudley, Evans, and John (1998), is that it is likely to be designed for adult learners and it is intended for intermediate or advanced students. This requirement is suitable for the characteristics of CED students, that most of the students are at intermediate level. They are used to learn English emphasizing on grammar mastery and communicative competence. The students' background knowledge can support the learning ECE at CED. This condition may be used as the primary reference in deciding appropriate learning materials in the learning ECE. The students also need the use of interactive media to improve the quality of learning process. In addition, the students said that the classroom condition to learn ECE was entirely comfortable with the learning process, but the environment does not support the learning.

From the result of the learning needs analysis above it is clear that there are some issued that can be considered as main problems in the previous ECE learning process. First, teaching methods need to be improved. The use of teaching methods such as role play and group discussion requires much time while the available time is only limited, two hours, once a week. Therefore, the learning materials designers should find a solution to cover these learning needs. Second, there is a gap between existing $\mathrm{z}$ materials and expected materials, so that the new learning materials need to be developed which refers to the need of the current target situation. Third, the environment did not support the learning. Last, the issue related to time constraints.

\section{Target Needs}

The target needs analysis revealed some important information about the learning material development purpose related to what the learners need to do in the target situation. This analysis provided the information about the importance of English in the workplace are related to topics commonly talked, English skills needed, and how English is used at workplace.

The first target needs analysis is related to topics commonly talked. The topics needed are analyzed based on the frequency of certain topics communicated in the target situation that can be classified into two classifications, subject, and level. They can be seen in table 1 below.

\begin{tabular}{|c|c|c|c|c|c|}
\hline \multirow{2}{*}{\multicolumn{2}{|c|}{ Data Transcription }} & \multicolumn{3}{|c|}{ Company } & \multirow{2}{*}{ Av. } \\
\hline & & A & $\mathrm{B}$ & $\mathrm{C}$ & \\
\hline \multicolumn{6}{|c|}{ Subject: } \\
\hline a. & Mathematics & 3 & 3 & 3 & 3 \\
\hline b. & Physics & 3 & 2 & 2 & 2,3 \\
\hline c. & Chemistry & 2 & 2 & 3 & 2,3 \\
\hline d. & Building materials & 4 & 3 & 3 & 3,3 \\
\hline e. & Construction area & 3 & 3 & 3 & 3 \\
\hline f. & Energy & 2 & 2 & 2 & 2 \\
\hline g. & Survey & 2 & 2 & 2 & 2 \\
\hline h. & Jobs in building industry & 3 & 2 & 3 & 2,6 \\
\hline i. & Civil engineering tools & 3 & 3 & 3 & 3 \\
\hline & Buildings structure & 3 & 3 & 3 & 3 \\
\hline $\mathrm{k}$. & Data, graphic, diagram & 3 & 3 & 4 & 3,3 \\
\hline 1. & Works instructions & 3 & 3 & 2 & 2,6 \\
\hline $\mathrm{m}$. & Job application & 3 & 3 & 3 & 3 \\
\hline \multicolumn{6}{|c|}{ Level } \\
\hline & Basic & 3 & 2 & 4 & 3 \\
\hline & Intermediate & 3 & 4 & 3 & 3,3 \\
\hline p. & Advanced & 3 & 4 & 3 & 3,3 \\
\hline
\end{tabular}


Table 1 above revealed that related to the subject, type of the topics needed are mathematics, contract agreement, civil engineering tools, building materials, construction area, civil engineering tools, building structure, data, graphic, diagram, and job application. Related to level, the three levels of skills are needed, they are basic, intermediate, and advanced level. These topics should be correlated with English language skills needed and used at workplace.

The second analysis is related to English skills needed and how English is used at workplace. The frequency of English skills needed and used at workplace related to medium, channel, and types needed by the learners can be seen in table 2 below.

\begin{tabular}{|c|c|c|c|c|}
\hline \multirow{2}{*}{ Data Transcription } & \multicolumn{3}{|c|}{ Company } & \multirow{2}{*}{ Av. } \\
\hline & $\mathrm{A}$ & $\mathrm{B}$ & $\mathrm{C}$ & \\
\hline \multicolumn{5}{|l|}{ Medium } \\
\hline a. $\quad$ Speaking & 2 & 3 & 2 & 2,3 \\
\hline b. Listening & 2 & 3 & 3 & 2,6 \\
\hline c. Reading & 3 & 3 & 3 & 3 \\
\hline d. Writing & 3 & 3 & 3 & 3 \\
\hline \multicolumn{5}{|l|}{ Channel } \\
\hline e. Telephone & 2 & 3 & 2 & 2,3 \\
\hline f. Face to face & 2 & 3 & 3 & 2,6 \\
\hline g. Internet & 3 & 3 & 3 & 3 \\
\hline \multicolumn{5}{|l|}{ Type of texts } \\
\hline h. Formal Conversation & 3 & 2 & 3 & 2,6 \\
\hline i. Informal Conversation & 2 & 2 & 2 & 2 \\
\hline j. Presentation & 3 & 3 & 3 & 3 \\
\hline k. Giving Instruction & 2 & 3 & 3 & 2,6 \\
\hline 1. Description of place & 2 & 2 & 3 & 2,3 \\
\hline m. Reading manual book & 2 & 3 & 3 & 2,6 \\
\hline n. Writing report & 4 & 3 & 3 & 3,3 \\
\hline o. Writing minutes of meeting & 3 & 3 & 3 & 3 \\
\hline p. Memo & 3 & 3 & 2 & 2,6 \\
\hline q. E-mail & 3 & 3 & 3 & 3 \\
\hline r. Proposal & 3 & 3 & 4 & 3,3 \\
\hline s. Writing business letter or letter of bid & 4 & 3 & 4 & 3,6 \\
\hline t. Contract of agreement & 3 & 3 & 3 & 3 \\
\hline
\end{tabular}

From the result of target needs analysis in table 2 above, it can be seen that most companies of Civil Engineering are using English for communication with the internal and external party. The communication mostly happens to the external party using English. The medium of communications mostly used are written text. Therefore, reading and writing skills are needed by the students (score 3). Speaking and listening skills are less frequently used (score 2,3 and 2,6 respectively). Among the three channel (telephone, face to face, and internet), the internet was the most commonly used (score 3). The types of text mostly used are writing business letter or letter of bid $(3,6)$, proposal $(3,3)$, report $(3,3)$. The next are writing minutes meeting, e-mail, contract agreement, and presentation (scores 3 ). So, the learning materials should reflect those needs.

To facilitate the learning reading and writing, the materials of ESP should use authentic texts. Hirvel in Paltridge \& Sue (2013) argue that with the emphasis on authentic texts drawn from various disciplinary or vocational communities and the analysis of their properties as forms of discourse, ESP was positioning reading, like writing, as a situated activity. In addition, Zaim, Djoni, \& Mukhaiyar (2015) state that the students are interested in the reading materials which is relevant with the topic from any resources such as from the internet, newspaper, and described them into a graphic. Therefore, the types of text given should be relevant to the job that the students will acquire after graduating from CED.

Teaching reading and writing should focus on specific genre used in Civil Engineering field. Hayland in Paltridge \& Sue (2013) states that ESP conceptions of writing focus on assisting students towards competence in particular target genres. Teachers do not only "teach writing" but teach specific kinds of writing which are valued and expected in some academic or professional contexts. The materials focus on competence and genre used in target situation of a major field. This is the difference between ESP writing and EGP writing. By considering the priority skills used in the construction and its content, the language focus based on the needs analysis are writing a business letter or letter of the bid, writing a report, minutes of the meeting, contract agreement, and manual book. This is in line with Kaewpet (2009), and Heidenreich (2008)who state that writing and reading skills are necessary for email, reports, letters, memos, and meeting minutes. Writing business letter is the most needed and followed by writing report and minutes of the meeting. It means that reading and writing are the important skills to support the primary profession of a person in building industries. It also strengthens that Civil Engineer rarely required communicating verbally.

The other skills, listening, and speaking are less important. In the civil engineering field, speaking and listening are not the primary communication skills because the goal of verbal communication can be understood each other. The grammatical rules are not really noticed. Handford and Matous in Paltridge \& Sue (2013) argue that, in construction, the grammatical accuracy was found less important than the ability to understand nonverbal forms of communication. Interestingly, contractors working at 
construction sites, require an "ability to encode and understand the symbols which carry meaning (such as diagrams and photographs)." The grammatical rules are not the priority. The main goals are the message which is delivered in communication. To have successful communication, some speaking strategies should be used by the speaker such as compensation strategy. Furthermore, Handford and Matous in Paltridge \& Sue (2013:41) state that nonverbal communication skills, including gesturing, are instrumental for successful communication in construction environments with high noise levels and where speakers have a "high level of shared professional knowledge, and a relatively less confident grasp of the language (when compared to the speakers' L1s)". Speaking skill is considered as successful if the speaker uses nonverbal communication which means they understand the message. In addition, Zaim, Ardianyah, and Refnaldi (2015) state the ways successful students use compensation strategy of speaking by coining words, using circumlocution or synonym, using gesture, and adjusting the message.

Feak in Paltridge \& Sue (2013) state that in some ESP speaking contexts, besides language, matters of cross-cultural awareness may be essential in the curriculum, as suggested by the needs analysis of mountain guides and medical professionals. Other relevant considerations in curriculum design include how and when to integrate pragmatics into a curriculum best. The learning materials design should focus more on reading and writing materials activities without ignoring the listening and speaking skills. The language focuses correlate with these topics and skills needed for target situation.

\section{CONClusion AND RECOMMENDATION}

The learning needs analysis found some of the important things that should be applied in learning ECE. The English skills which are mostly needed for Civil Engineer are writing and reading skill, the learning process should use communicative teaching methodologies, such as role play and group discussion, and the students need an environment which can support and stimulate them in learning ECE. Target needs analysis found that there are topics and language focuses related to civil engineering profession which is needed to be added to ECE learning materials. The new topics are building materials, civil engineering tools, technical specifications, project status, and tender for the contract. The new language focuses are a memo, report, formal conversation, and expression of interest. These findings, learning needs, and target needs can be used as a reference in developing learning materials. The learning needs and target needs found in learning English for Civil Engineering subject at Civil Engineering Department can be a reference for the curriculum designer in developing learning materials, teaching methodology, and learning strategies of English for Civil Engineering subject in higher education.

\section{Acknowledgment}

The writer would like to express appreciation to the chairman, lecturer, and students of Civil Engineering Department of Universitas Negeri Padang, and PT. Adhi Karya (Persero) Tbk., PT. Griksa Cipta, and PT. Yaika Gema Utama who helped the writer in giving useful information during the interview and completing the questionnaire.

\section{References}

Basturkmen, H. (2006). Ideas and Option in English for Specific Purposes. New Jersey: Lawrence Erlbaum Associates Publishers Brown, J. D. (1995). The Elements of Language Curriculum. Boston, Massachusetts. Heinle \& Heinle Publishers:

Chovancova, B. (2014). Needs Analysis and ESP Course Design: Self-Perception of Language Needs Among Pre-Service Students. The Gruyter - Studies in Logic, Grammar, and Rhetoric, 43-57, Retrieved on July 21, 2017

Creswell, J. W. (2008). Educational Research: Planning, Conducting and Evaluating Quantitative and Qualitative Research. New Jersey: Pearson Education, Inc.

Dudley-Evans, T. \& John, M. (1998). Developments in English for specific purposes: A multidisciplinary approach. Cambridge: Cambridge University Press

Gay, L. R. (2009). Educational Research: Competencies for Analysis and Applications. New Jersey: Ohio

Harding, K. (2007). English for Specific Purposes. Cambridge: Cambridge University Press

Heidenreich, S. (2010). Englisch fur Architekten und Bauingenieure - English for Architects and Civil Engineers. Nurenberg: Vieweg+Teubner Verlag Springer

Hutchinson, T, and Waters, A. (1987). English for Specific Purposes. Cambridge: Cambridge University Press

Kaewpewt, C. (2009). A Framework for Investigating Learner Needs: Needs Analysis Extended to Curriculum Development. Electronic Journal of Foreign Language Teaching, 6: 209-220

Marsh, D. (2012). Blended Learning; Creating Learning Opportunities for Language Learners. New York. Cambridge University Press

Nation, I. S. P, and Macalister, J. (2010). Language Curriculum Design. New York: Routledge

Paltridge, B \& Starfield, S. (2013). The Handbook of English for Specific Purposes. Boston: John Wiley \& Sons Inc.

Pratt, D. (1980). Curriculum: Design and Development. New York: Harcourt Brace

Richards, J. C. (2001). Curriculum Language Development in Language Teaching. Cambridge: Cambridge University Press

Robinson, PC. (1991). ESP Today: A Practitioner's Guide. London: Prentice Hall.

Seel, N. M, and Dijkstra, Sanne. (2008). Curriculum, Plans, and Processes in Instructional Design: International Perspectives, Edited by. Lawrence Erlbaum Associates, Inc. 
Spence, P., \& Liu, G. Z. (2013). Engineering English and the high-tech industry: A case study an English needs analysis of process integration engineers at a semiconductor manufacturing company in Taiwan. English for Specific Purposes, 32 (2), 97-109. https://doi.org/10.1016/j.esp.2012.11.003

Yasin. A.Y.M, Shaupil, M. H, W. M., Mukhtar, A.M., Ghani, N.I. A., \& Rashid, F. (2010). The English Proficiency of Civil Engineering Students at a Malaysian Polytechnic. Asian Social Science, 6 (6), 161-170. DOI: http://dx.doi.org/10.5539/ass.v6n6p161

Zaim, M, Ardiansyah \& Refnaldi. (2015). An Analysis of Language learning Strategies of Speaking used by successful and unsuccessful students of Semester III English Department of IAIN Sultan Thaha Saifuddin Jambi. Journal English Language Teaching, (1) 1.

Zaim, M, Djoni, \& Mukhaiyar. (2015). Improving Students' Reading Comprehension of Analytical Exposition Text by Using Graphic Organizers at Grade XI Social Science of SMA Kalam Kudus Padang. Journal English Language Teaching, (1) 1. 